\title{
Challenges of COVID-19 Vaccination in Iran: In the Fourth Wave of Pandemic Spread
}

\author{
Mohammad Heidari, $\mathrm{PhD} ;^{1} \odot$ Hamid Jafari, $\mathrm{PhD}^{2} \odot$
}

1. Community-Oriented Nursing Midwifery Research Center, Shahrekord University of Medical Sciences, Shahrekord, Iran

2. Sirjan School of Medical Sciences, Sirjan, Iran

Correspondence:

Hamid Jafari, $\mathrm{PhD}$

Sirjan School of Medical Sciences, Sirjan, Iran E-mail: hjafari68@gmail.com

Conflicts of interest/funding: The authors report no conflicts of interest. The authors alone are responsible for the content and writing of the paper.

Keywords: Iran; pandemic; politics; vaccination

Abbreviation:

COVID-19: coronavirus disease 2019

Received: May 5, 2021

Accepted: May 20, 2021

\section{doi:10.1017/S1049023X21000777}

(C) The Author(s), 2021. Published by Cambridge University Press on behalf of the World Association for Disaster and Emergency Medicine.
Heidari M, Jafari H. Challenges of COVID-19 vaccination in Iran: in the fourth wave of pandemic spread. Prehosp Disaster Med. 2021;36(5):659-660.

According to the official statistics of the Ministry of Health (Tehran, Iran), from the beginning of the outbreak of coronavirus disease 2019 (COVID-19) in Iran until May 3, 2021, nearly 2,555,587 people have been diagnosed with COVID-19 in the country and 72,875 people with this disease have lost their lives. ${ }^{1}$ The Islamic Republic of Iran is ranked $14^{\text {th }}$ in the world in terms of the number of patients, regardless of population, and is the most affected country in the world after Turkey in this pandemic. ${ }^{2}$ Charts show the spread of the fourth wave of COVID-19 in the country, which is wider than previous waves of the virus (Figure 1). Due to the prolongation of the pandemic, people are less likely to follow health protocols. The British version of the virus (B.1.1.7) has spread across the country, raising concerns about causing a national catastrophe. Between 400 and 500 people die every day in the country due to COVID-19, which is a high figure considering the population of 80 million people in Iran. ${ }^{3}$

Vaccination of citizens in Iran began in February 2021 with a limited number of Russian Sputnik V COVID-19 vaccines. However, the total number of vaccines that arrived in Iran three months later was less than 900,000 doses. Many other promises made by officials have so far relied on an agreement or registration of an order and request for vaccine, which has often failed to materialize. ${ }^{4}$ In terms of vaccinating citizens, Iran lags far behind (with the exception of a few countries in the region, such as Afghanistan) and has not taken the first steps compared to a country like Turkey with an almost identical population. In Turkey, more than 20 million doses of vaccine were injected by April 2021, while this number in Iran did not exceed 718,510 doses by the end of April 2021. ${ }^{5}$ Iran has high hopes for joint production of vaccines to meet domestic demand. Another such vaccine is scheduled to enter the third phase of a clinical trial soon in collaboration with the Pasteur Institute of Iran (Tehran, Iran) and the Cuban Finlay Institute (Playa, Havana, Cuba). Also, phase one of the Barakat vaccine has entered the clinical trial phase in the ethics committee due to providing the necessary documents after examinations, and a number of Chinese Sinofarm COVID-19 vaccines, Indian Bharat Biotech COVID-19 vaccines, and Oxford-AstraZeneca COVID-19 vaccines have also been imported into the country.

Medical staff are given first priority in receiving the vaccine, and the next priority includes high-risk groups such as the elderly and people with underlying diseases. All vaccines that were initially imported into the country are to be injected into first-line health care workers and medical staff at medical centers. However, due to the formation of the fourth wave of COVID-19 in the country, not all health care workers have been vaccinated yet. Besides, most people who have been vaccinated have received only one dose of the vaccine. ${ }^{6}$

The COVID-19 vaccine in Iran faces several fundamental challenges among the medical staff, including economic and political sanctions. For example, The Washington Post (Washington, DC USA) quoted financial and business analysts as saying that economic sanctions against Iran could disrupt the country's access to the COVID-19 vaccine, thus thwarting Iran's efforts to control the pandemic and perpetuating the prevalence of this disease in the region. ${ }^{7}$ Although the spokesman for the global COVID-19 vaccine program, called "COVAX," says the United States has exempted deals related to the vaccine from sanctions, analysts warn that financial sanctions will limit Iran's efforts to participate in the program, as well as the purchase of medical items. However, ensuring that international companies can deliver these vaccines to Iran requires redoubled efforts and targeted measures. With regard to political issues, Iran has restrictions on the import of the COVID-19 vaccine due to its special political ties. In January 2021, the Iranian leader banned American and British vaccines from entering the country for political reasons. 


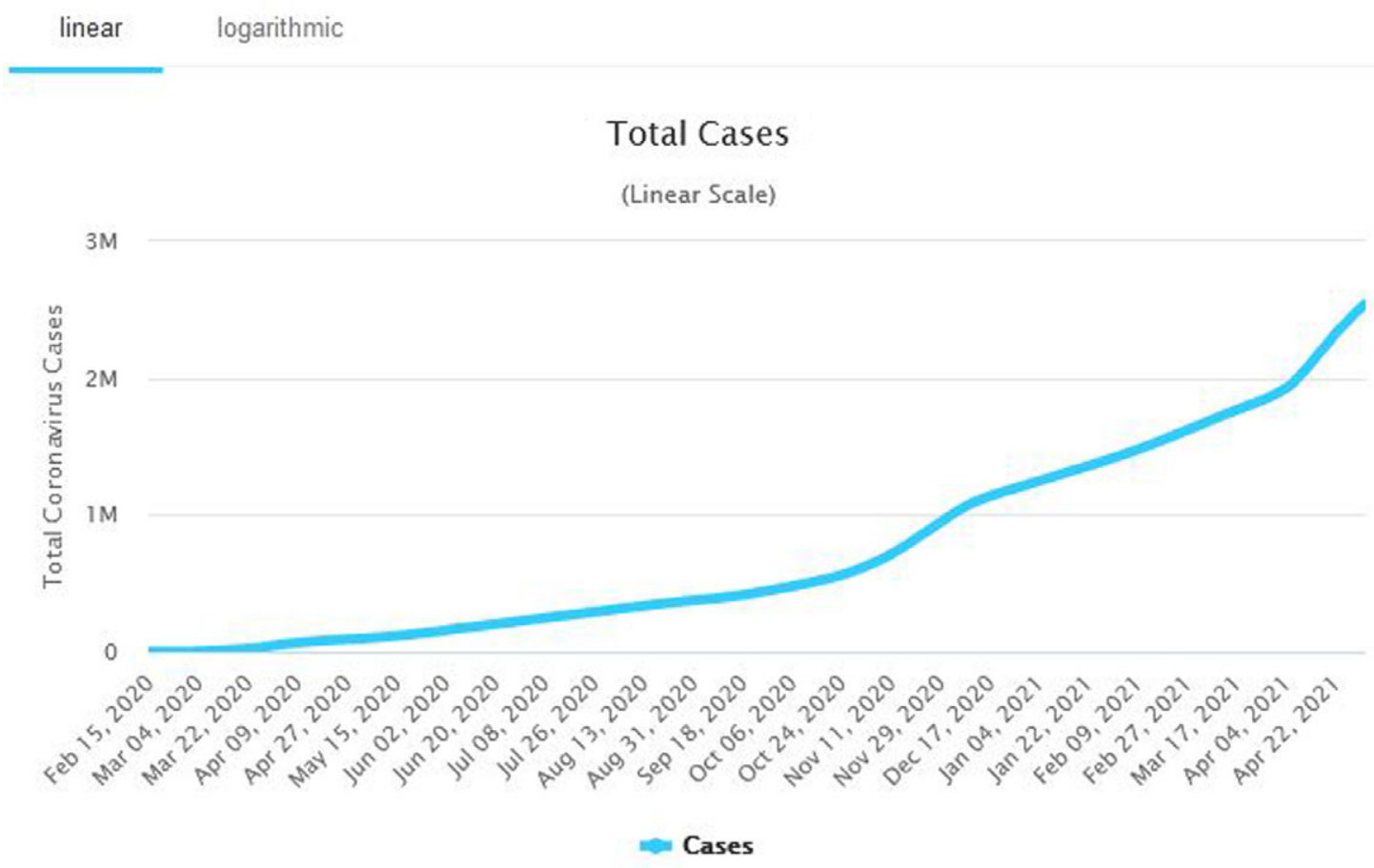

Figure 1. Total Coronavirus Cases in Iran.

Heidari $\odot 2021$ Prehospital and Disaster Medicine

Since then, Iran has made most of its efforts to purchase the Sputnik V COVID-19 vaccine, as well as signing agreements with countries such as China, India, and Cuba, focusing on domestic production of the vaccine. The next challenging issue is trust; due to the lack of trust in the country, most medical staff have less confidence in the Sputnik V COVID-19 vaccine and are concerned that the information on the effectiveness of the vaccine is not well available, and so are not interested in injecting such vaccines. On the other hand, receiving reports of blood clot formation after the injection of the Oxford-AstraZeneca vaccine has made many people reluctant to receive this vaccine. ${ }^{8}$

COVID-19 vaccination faces several challenges in developing countries such as Iran, in such a way that cultural, political, social, and economic issues affect the vaccination process. Given that the health of countries is interdependent, it is better to design an international mechanism independent of economic, political, and social issues to be able to continue the process of vaccination in the world more effectively.

\section{References}

1. World Health Organization. Coronavirus Disease (COVID-19): Situation Report, 200.

Geneva, Switzerland: WHO; 2020.

2. Devi S. COVID-19 resurgence in Iran. Lancet. 2020;395(10241):1896.

3. Raeisi A, Tabrizi JS, Gouya MM. IR of Iran national mobilization against COVID-19 epidemic. Archives of Iranian Medicine. 2020;23(4):216.

4. Jafari H, Gharaghani MA. Cultural challenges: the most important challenge of COVID-19 control policies in Iran. Prehosp Disaster Med. 2020;35(4):470-471.

5. Corona vaccination in Iran; promises and facts. Deutsche Welle Persian. https://p.dw. com/p/3sV5z. Accessed May 1, 2021.

6. Zandi M, Rashid S, Nasimzadeh S, Pourhossein B, Fazeli M. A snapshot of different types of under research vaccines against COVID-19: a review. Archives of Medical Laboratory Sciences. 2020;6:1-7.

7. Dehghani M, Mesgarpour B, Akhondzadeh S, Azami-Aghdash S, Ferdousi R. How the US sanctions are affecting the health research system in Iran. Archives of Iranian Medicine. 2021;2

8. Mirzaee S, Jalalinejad R, George B. Country of Origin, COVID-19 Vaccine, and the Future of Travel: A Preliminary Study in Iran. Anais Brasileiros de Estudos Turísticos-ABET. 2021. 